\title{
Living with buildings. Wellcome Collection, London, 4 October 2018 - 3 March 2019
}

\author{
Dr Evangelia Chrysikou
}

The Bartlett Real Estate Institute, University College London, UK

\begin{abstract}
A review of the recent exhibition 'Living with buildings: health and architecture', curated by Emily Sargent at the Wellcome Collection.
\end{abstract}

The exhibition Living with buildings: health and architecture reflects on a topic that is relevant to everybody. It explores the entire scale of the built environment, from the most private context of housing to the broad context of public space. Regarding health, it contains the entire spectrum of the world health meaning: physical, mental, individual people's health as well as the health of the public, health as a component of a broader state of wellbeing and the absence of health as captured by the need to provide healthcare. Chronologically, the exhibition spans from the recent past to the present and even catches a tiny glimpse of the future. This is because, in a separate room attached to the main exhibition Living with buildings hosts the prototype of the Global Clinic, a mobile clinic for the Doctors of the World, before its first deployment.

For the general public, the fact that the environment relates to health should come as no surprise. Especially people who have experienced vulnerability could relate to this. Yet, the contents of the exhibition could directly benefit all those involved in the design, commissioning and construction of buildings, as it explores the impact of their decisions to people's physical and mental health. This acceptance of the responsibility involved, could be traced all the way back to policy. This is both timely and important: even though responsibility corresponds to all stages of a building's lifecycle as Grenfell Tower disaster has taught us, it is not always perceived and accepted. The fact that the exhibition takes place inside the Wellcome building as opposed to a space connected with the built environment is perhaps an indication of this.

The exhibition presents a broad range of buildings, which cater for health prevention as well as health restoration. Regarding the first, housing is a recurring theme and it is covered in a very comprehensive way. Then, there is space in the exhibition for specialized buildings for health, i.e. healthcare facilities. 
The angle that these are viewed is through a normative architectural perspective, very much in consistence to the non-medical buildings.

Spatially, the exhibition is organized in two main sections. The first I would describe as the past and present section. This is mostly expressed by documents brought in to represent the meaning and ambience of places that existed or exist outside the Wellcome building. The second section, which is hosted in another floor without visual connection to the first part, comprises a healthcare building that has not yet been used as such but it is going to be employed in a location where Doctors of the World operate after the end of the event. For this, I would consider it a near-future project.

The main section brings together two main themes: the housing and the healthcare delivery buildings. In the housing section, the curator introduces the theme using Charles Dicken's quote on the connection between poverty, potential for prosperity and building conditions. Under this political statement, the visitor is familiarised to the appalling conditions of the slums because of the industrialization and the need of large numbers of people to move and live close to factories. Options of healthier, greener communities and secure communities, such as Bedford Park, marketed as the "Healthiest Place on Earth" were reserved to the few who could afford them. The rare exceptions of workers who could experience salutogenic built environment conditions were those working for idealist industrialists who invested in creating the infrastructure for utopian communities. Such was the case of Cadburys brothers, founders of Bournville town influenced by the Quakers principles connecting health, nature, hygiene, education and employment.

The curator stands at the post Second World War period as the timing when most the people acquired was access to healthy built environment. This was materialized through wide development of high-rise buildings and the ideology of Modernism. New, functional buildings that allow for green and communal spaces, ventilation and orientation were equipped with sanitary facilities for hygiene and available to those in need through welfare provision. The socially conscious architecture of Enro Goldfinger is presented for its' idealistic principles. Yet, we do get of the dire reality in these spaces. Accidents, such as the Ronan Point explosion in New Castle in 1968, anti-social behaviours and dangerousness erased the good intentions and resulted in a situation where all options turned out to be possible: demolition, repurposing -to ironically landmark real estate such as the cult Trellick Tower and now Balfron Tower (Figure 1) - or gradual transformation of these buildings to vertical slums. In the last two cases we are confronted by the lack of accountability towards the most vulnerable: either by them being denied the 
choice to return to their homes after improvements or being the victims of chain comprising of several weak links as in Grenfell Tower.

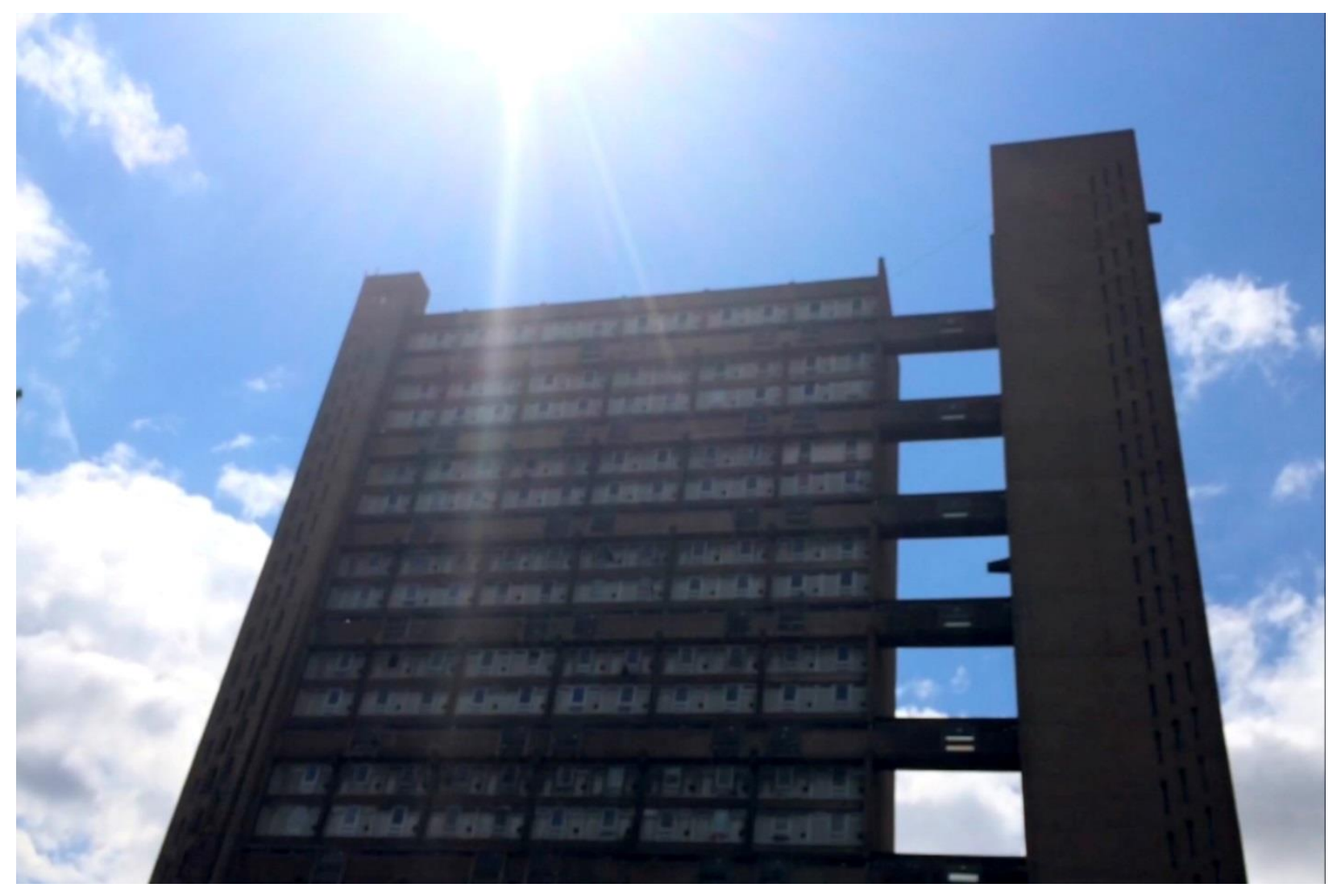

Figure 1: Rab Harling, still from Inversion/Reflection: What does Balfron Tower mean to you?, 2014. Credit: (C Rab Harling

For the Healthcare delivery section the spectrum concentrates on how the major movements of normative architecture perceive design for healthcare. Alvar Aalto, one of the most influential Modernists was the architect behind the 1932 Paimio Sanatorium that is one of the key buildings to be featured in the exhibition. The Sanatorium was designed using principles that would result in a building that promotes hygiene (Figure 2). The architecture of the Sanatorium uses the sun and the wind as therapeutic tools. Since the patients who used the facility suffered from Tuberculosis (TB), this was following medical requirements making the building fit for purpose. Yet, the same principles apply to other iconic modernist healthcare architecture presented such as the Finsbury Health Centre but at the same time is close to other healthcare facilities that were designed by Modernists and were not focused on TB such as the hospital that Le Corbusier designed for Venice (Psara, 2018). 


\section{noiseless wash-basin}

No noises, no water splashes when washing your hands in running water, because the basin-china is in position of 45 degrees.

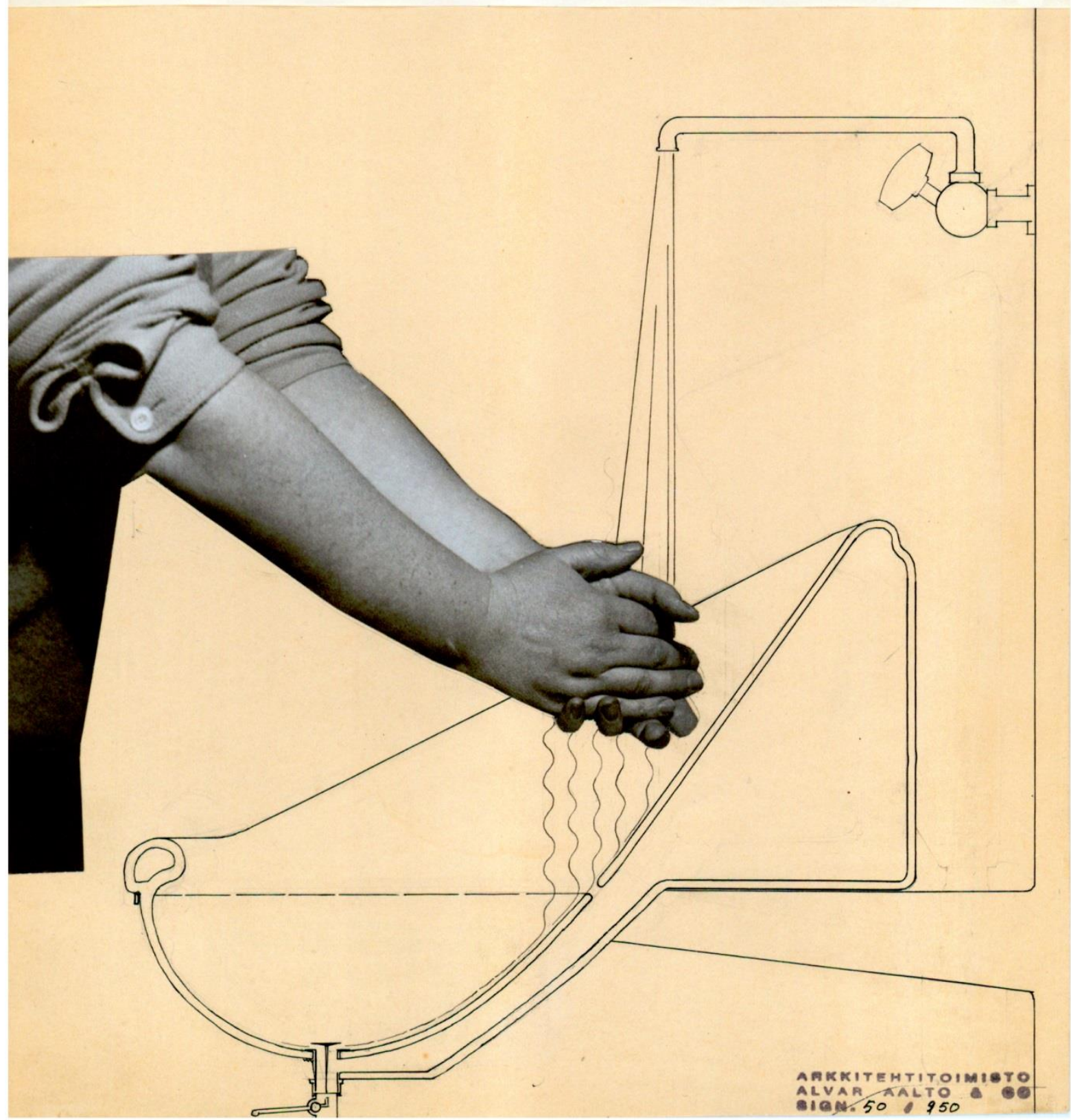

Figure 2: Alvar Aalto, Noiseless Washbasins, 1932. Credit: Alvar Aalto Foundation 
This angle of approaching healthcare buildings, from the perspective of the normative architecture and especially through the lens of the architectural Avant garde, rather than prioritising clinical implications, physiology or resources, was challenged when an architect that was part of the architectural elite was confronted with the devastating experience of an obsolete medical model and an under-resourced service. The person, Maggie Jenkins, channeled the power of her end-of-life realisation to change the way that architects perceive and value medical environments, from functional to inspirational and at the same time help provide for the patients places they would feel at ease. By writing the brief of the Maggie's cancer facility (Maggie's, 2015), she sparked the creation of the Maggie's Centres. These motivated distinguished architects to be involved in healthcare projects and the same time supported the already brewing patient focused advocates of healthcare architecture (Chrysikou, 2018; Dilani, 2002) to back compassionate models.

Finally the first part of the exhibition includes the new book by lain Sinclair, Living with Buildings. The book is inspired by the exhibition, and published by Wellcome Collection and Profile Books.

The second part of the exhibition develops around the Global Clinic created by architects Rogers Stirk Harbour + Partners, engineers Buro Happold and Chapman BDSP and the Doctors of the World (Figure 3). This is an actual healthcare facility, a prototype, specifically design and manufactured to be easily transportable, inexpensive, easy to assemble and at the same time fit for purpose to be deployable to places facing humanitarian crises. It is a locus for medics of Doctors of the World that can be adjusted to needs. The Wellcome collection is the first stop of that prototype but it will not be the last. After the end of the exhibition, this 1:1 scale model will be re-assembled in a place where it can make a difference in actual people's health. 


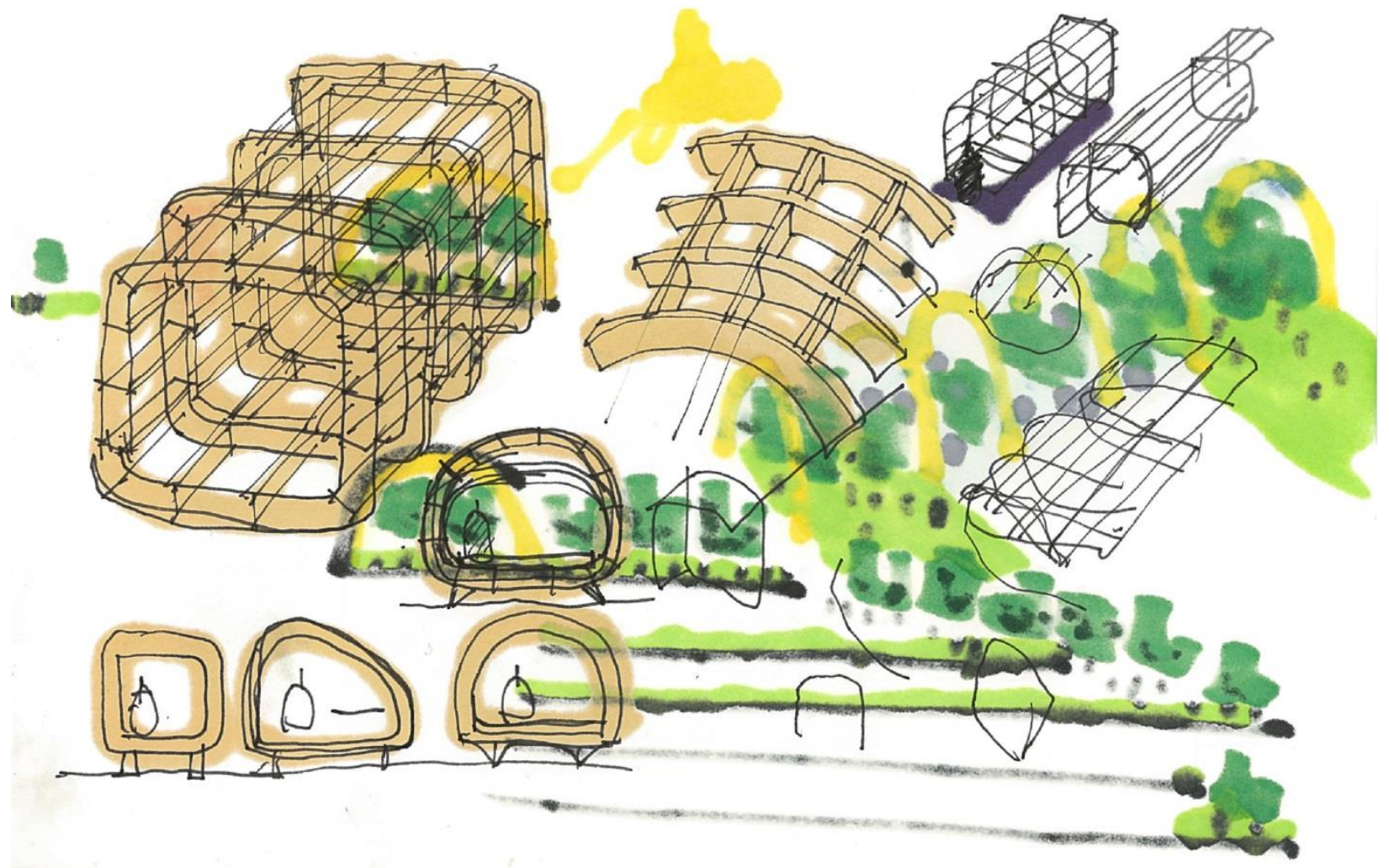

Figure 3: Concept sketch for Doctors of the World project, 2018 Credit: Rogers Stirk Harbour + Partners

Living with buildings is not a healthcare architecture exhibition. It is an exhibition about buildings and the health of the public, as World Health Organisation would define it (World Health Organisation, 1998). Our housing stock linked to our existence as we all need a clean and dry space to sleep and at the same time we need a place to call home that feels safe and where we see our personal stories develop. The unexpected disruption of this continuity as demonstrated by the personal narratives could lead in a loss of our sense of coherence. The housing section demonstrates in a very eloquent manner the connection between health, environment and politics. The exhibition uses multiple media to deliver a message that poverty, limited choice and exclusion from decision-making in subjects related to our houses can affect our physical and mental health. It demonstrates that this was happening during the Dickensian period and might still happen when market economics cast aside people's health and wellbeing through the repurposing of the housing estates, the loss of former residence's sense of community and the acceptance of substandard solutions for existing estates.

Living with buildings does not focus on the complexity of the hospitals of the $20^{\text {th }}$ Century, the theories that influenced them or the health policy and finance as normally a healthcare architect might view 
them. That would be closer to a newer definition of public health, the one by the European Public Health Association (EUPHA), where public health "includes the broader area of public health, health services research, health service delivery and health systems design"(EUPHA, 2019). Thus, landmarks of specialized healthcare architecture, such as the Planetree hospitals for a patient centre approach

(Frampton et al, 2008) or even functional, resource led schemes such Nucleus (British Medical Journal, 1976) - all influential for healthcare architects but which have not yet entered the radar of normative architecture - were not included in the concepts explored. This leaves space for more exploration on the topic, a very significant topic for medical humanities, on restorative spaces and spaces for healthcare in the future.

\section{Disclosure statement}

No potential conflict of interest was reported by the author.

\section{Notes on contributor}

Evangelia Chrysikou is Lecturer and Program Director for the MSc Healthcare Facilities at the Bartlett Real Estate Institute, UCL, London. Medical architect holding a rare PhD on mental health (UCL) and a former Marie Curie H2020 Fellow. Actively involved in policymaking. Coordinator of the D4 Action Group, European Innovation Partnership on Active and Healthy Ageing (EIP on AHA), European Commission (EC). Vice-President of the Urban Health Section, EUPHA. Consulted for the EC, the Hellenic Ministry of Health and the Centre of European Constitutional Law on legislation for psychiatric facilities. Multi-awarded (Singapore 2009, Kuala Lumpur 2012, Brisbane 2013, Birmingham 2014, London 2014, Vienna 2017). Researched mental health, ageing, accessibility, autism, social inclusion, healthcare and wellness buildings and medical tourism planning in several contexts (UK, France, Belgium, Greece, Netherlands, Israel, Qatar, Japan, New Zealand). Funded by the EC (H2020), the Great Britain Sasakawa Foundation (Butterfield), the Royal Society of New Zealand (Marsden) and Onassis Foundation. Authored national guidelines for psychiatric facilities for Greece on behalf of the EU, books ('Architecture for Psychiatric Environments and Therapeutic Spaces', 'The Social Invisibility of Mental Health Facilities'). Journal editor, reviewer, active member of professional and scientific associations, TED-MED speaker. 
ORCID

Evangelia Chrusikou https://orcid.org/0000-0002-7894-6053

\section{References}

British Medical Journal. 1976. Editorial: Nucleus hospitals. Br Med J 31; 1(6004): 245-246

Chrysikou, E. 2018. 'Why we need new architectural and design paradigms to meet the needs of vulnerable people'. Palgrave Communications 4(116), doi: 10.1057/s41599-018-0171-z.

Dilani A (2000) 'Healthcare buildings as supportive environments'. World hospitals and health services: the official journal of the International Hospital Federation 36(1): 20-6

EUPHA. 2019. Who we are. Accessed 23 January 2019: https://eupha.org/who-we-are

Frampton, S., Charmel, P., Planetree. 2008. Putting Patients First: Best Practices in Patient-Centered Care, 2nd Edition. New York, NY: Jossey-Bass

Maggie's. 2015. Maggie's Architecture and Landscape Brief. Accessed 20 January 2019:

https://www.maggiescentres.org/media/uploads/publications/otherpublications/Maggies architecturalbrief 2015.pdf

Psarra, S. 2018. The Venice Variations: Tracing the Architectural Imagination. London: UCL Press

World Health Organisation. 1998. 'Health Promotion Glossary'. Geneva: World Health Organisation 